BMJ Open Sport \& Exercise Medicine

\title{
Sports-related acute shoulder injuries in an urban population
}

\author{
Martine Enger, ${ }^{01,2}$ Stein Arve Skjaker, ${ }^{1}$ Lars Nordsletten, ${ }^{1,2}$ Are Hugo Pripp, ${ }^{3}$ \\ Knut Melhuus, ${ }^{1}$ Stefan Moosmayer, ${ }^{4}$ Jens Ivar Brox ${ }^{2,5}$
}

To cite: Enger M, Skjaker SA, Nordsletten L, et al. Sportsrelated acute shoulder injuries in an urban population. $B M J$ Open Sport \& Exercise Medicine 2019:5:e000551. doi:10.1136/ bmjsem-2019-000551

- Additional material is published online only. To view please visit the journal online (http://dx.doi.org/10.1136/ bmjsem-2019-000551).

Accepted 24 July 2019

Check for updates

(c) Author(s) (or their employer(s)) 2019. Re-use permitted under CC BY-NC. No commercial re-use. See rights and permissions. Published by BMJ.

${ }^{1}$ Division of Orthopaedic Surgery, Oslo University Hospital, Oslo, Norway

${ }^{2}$ Institute of Clinical Medicine, University of Oslo, Oslo, Norway ${ }^{3}$ Oslo Centre of Biostatistics and Epidemiology, Oslo University Hospital, Oslo, Norway ${ }^{4}$ Department of Orthopaedic Surgery, Martina Hansens Hospital, Baerum, Norway ${ }^{5}$ Department of Physical Medicine and Rehabilitation, Oslo University Hospital, Oslo, Norway

Correspondence to Dr Martine Enger; uxrten@ous-hf.no

\section{ABSTRACT}

Objectives More than a third of sports injuries involve the upper extremity. The primary aim was to quantify and describe sports-related shoulder injuries in a general population cohort. A secondary aim was to compare aspects of these injuries to those that were not sportsrelated.

Methods We performed a prospective registration of the activity at the time of shoulder injury in all cases admitted during 1 year in a combined primary care and orthopaedic emergency department serving a defined population. The electronic patient records and patient reported questionnaires were reviewed.

Results Twenty-nine per cent $(n=781)$ of 2650 registered shoulder injuries were reported to be sportsrelated, with the highest proportion in acromioclavicular injuries (>50\%). Patients with sports injuries were younger than those injured during other activities (median age 28 and 43 years, respectively, $p<0.001$ ), and more often male (78\% and $52 \%$, respectively, $p<0.001)$. There was a strong gender disparity in incidence of sports-related shoulder injuries in adolescents and young adults, which was not observed in non-sports shoulder injuries. Football (soccer) (6-29 years), cycling (30-49 years), skiing (50-69 years) and martial arts were the dominating sports activities. Fractures were more common in skiing and cycling than in other major sports in the study.

Conclusions Almost a third of the shoulder injuries occurred during sports. The types of sports involved varied with age and gender. The comparison of sport to nonsport shoulder injury incidence rates suggests that the increased risk of shoulder injuries in young males is mainly attributable to sports injuries.

\section{INTRODUCTION}

More than a third of sports injuries involve the upper extremity. ${ }^{1}$ Shoulder injuries are of particular interest because of the high prevalence of self-reported shoulder pain in the general population, ${ }^{23}$ and the association of these symptoms with reduced health, limitations in daily living and absenteeism. ${ }^{45}$

Shoulder injury incidence rates are high in adolescents and young adults ${ }^{6}$; which are age groups likely to be active in sports. Existing data on shoulder sports injuries refer either to a limited subset of shoulder diagnoses, ${ }^{7-10}$ or all types of shoulder injuries limited to a

\section{What are the new findings?}

In this prospective study of 2650 shoulder injuries of all ages admitted at a large orthopaedic emergency department during 1 year, $29 \%$ of the injuries were sports-related.

- The most common sports associated with shoulder injuries were football, cycling, skiing and martial arts, but varied with age and gender.

- The results suggest that the increased general risk of shoulder injuries observed in young males is mainly attributable to sports injuries.

How might it impact on clinical practice in the future?

Knowledge of the typical shoulder injury diagnoses associated with the most common sports and age groups is an important element of the diagnostic process.

We recommend increased awareness of the strong impact of sports on shoulder injuries in the young and adult general population.

- The findings are important for the planning of preventive strategies.

specific sport. ${ }^{11-13}$ Shoulder sports injuries are also included in large population-based registry studies, ${ }^{1} 1415$ but there are to our knowledge no previous studies on acute sports injuries to the shoulder including all shoulder trauma diagnoses and age groups in a general population cohort.

The primary aim of this study was to quantify and describe sports-related shoulder injuries in an urban population. A secondary aim was to explore these injuries by comparing incidence rates, age, gender, proportion of main injury types and injury mechanism to the shoulder injuries that were not related to sports activity.

\section{PATIENTS AND METHODS}

Study design and setting

We carried out a prospective registration study of all patients admitted with a suspected shoulder injury at the Department of 
Orthopaedic Emergency, Oslo University Hospital from 1 May 2013 through 30 April 2014. The overall epidemiological patterns of shoulder injuries from this cohort have been published recently. ${ }^{6}$ In the present study, we have analysed the activity at the time of injury in the 2650 patients who were residents in the catchment area. Department of Orthopaedic Emergency is a combined primary care walk-in clinic and secondary care emergency department serving all hospitals and inhabitants of Oslo. Two previous studies report that $83 \%-86 \%$ of the population attended the department after upper extremity injury. ${ }^{1617}$ At the time of the study, the population was 632990 with a mean age of 37 years. ${ }^{18}$

In order to allow for data triangulation, ${ }^{19}$ we obtained information about the activity at the time of injury from the three following sources: (1) the national accident registration filled in by the patient (questionnaire given to the patients when admitted by the triage nurse, filled in by 1553 patients $(59 \%)$, (2) the same national accident registration filled in by the physician in the electronic patient record and (3) the physician notes in the electronic patient record.

\section{Data sources and registration criteria}

The electronic patient record system was used to identify cases with an International Classification of Diseases (ICD-10) S4 diagnosis (injuries of shoulder and upper arm). To check for missed cases and diagnostic coding mistakes, all patients who had filled in the questionnaire or had an ICD-10 M diagnosis (diseases of the musculoskeletal system and connective tissue) were systematically reviewed, and included in the registration according to the inclusion criteria.

Inclusion criteria were injury to the scapula, clavicle or the proximal third of the humerus, their articulations and adjacent soft tissues. The injury, with a coinciding onset of symptoms, should have occurred within the last 3 months of the first visit to Department of Orthopaedic Emergency. Patients with uncertain cause and or onset of the shoulder symptoms and no sign of acute injury on imaging, were excluded from registration $(0.6 \%$ of the patients who received a questionnaire).

In patients who experienced more than one incident resulting in a shoulder injury during the year of registration, each episode was recorded. We recorded each diagnosis in patients with multiple shoulder injuries from one mishap.

\section{Variables}

The registration included diagnosis, whether MRI was performed, age, gender and city district. The injury data registered included date and time of the incident, situation, activity, mechanism, type of location and geographical location. The first and second author reviewed all questionnaires and electronic patient records, and entered the data in the database.

We defined the incident as a sports injury if the patient had ticked off for sports/training as the ongoing activity when the injury occurred. In patients who had not filled in the questionnaire, we used the information from the other two listed sources. Both competitive, school and recreational sports were included. Twenty-one sports were listed in the patient questionnaire and electronic registration by the physician. If the box 'other sport' had been ticked off, identification of the sport was based on the physician notes in the medical records alone (marked with asterisk in table 1 ).

Fractures were diagnosed according to conventional radiographs that are routinely taken of all acute injuries that are not simple wounds. Occult fractures were registered when MRI or CT clearly concluded with a fracture. MRI was performed in 218 patients $(8 \%)$ of the cohort. Glenohumeral dislocations were normally diagnosed by conventional radiographs before and after reduction. Both primary and recurrent dislocations were included, as were patients with normal radiographs and either a history of prehospital reduction or signs of recent dislocation on MRI. Minor Hill Sachs and Bankart fractures were not registered as fractures. The diagnosis acromioclavicular dislocation or separation was used if the radiologist described a grade II-VI injury. ${ }^{20}$ In patients with localised tenderness over the acromioclavicular joint without abnormal widening of the joint space or coracoclavicular distance, the sprain diagnosis was used. ${ }^{21}$ The diagnosis of rotator cuff tear was based on clinical findings and MRI. ${ }^{22} 23$ The department's algorithm for follow-up of soft tissue shoulder injuries can be seen in the online supplementary file appendix 1. Screening all patients with MRI was neither possible nor desirable, as the presence of asymptomatic rotator cuff tears is well documented. ${ }^{24-26}$ In the age group at risk between 40 and 74 years with a soft tissue injury, $34 \%$ of the patients who had follow-up had MRI performed. Of these, $69 \%$ had a full-thickness or partial-thickness tear.

The first and second author reviewed the diagnosis by checking the electronic patient records including follow-up, radiology report(s) and in some cases images. We corrected the diagnosis when follow-up and or radiological examinations clearly concluded differently. We grouped the ICD-10 shoulder diagnoses into three main categories: soft tissue injuries, fractures and dislocations. Soft tissue injuries included contusions, distortions, open wounds as well as tendon and nerve injuries. Fractures of the upper third of the humeral bone, the clavicle and scapula were included in the fracture category, and dislocations of the glenohumeral joint, the sternoclavicular joint and grade II-VI injuries of the acromioclavicular joint in the dislocation category.

\section{Age groups}

We have used four age groups: 6-18, 19-29, 30-49 and $50-69$ years. The age group from 6 to 18 years was chosen because primary school starts at 6 years, and secondary school is most commonly finished at 18 years.

\section{Statistical analysis}

The data were analysed using IBM SPSS Statistics V.23. Age in patients with and without a sports-related injury 
was compared using the Wilcoxon test (Mann-Whitney $\mathrm{U}$ test) and described with medians and IQR as age was not normally distributed. We used logistic regression with pairwise comparisons in Stata to test for differences in the proportions of fractures and dislocations in sports with 25 or more injuries.

To explore the secondary aim, discrepancies in gender, main categories and injury mechanism between sports and non-sports injuries were analysed by the $\chi^{2}$ test.

Although relatively homogenous by international standards, the 15 administrative districts of Oslo vary somewhat regarding age and socioeconomic factors. To address potential bias, district residency was registered.

In accordance with Norwegian legislation, the Office of the Privacy and Data Protection Officer of Oslo University Hospital approved the study as an internal audit project with anonymous data which is exempt from the obligation to report to the Data Inspectorate and Regional Committee for Medical and Health Research Ethics. The study was performed in accordance with the Helsinki declaration.

\section{RESULTS}

Nearly every third patient $(\mathrm{n}=781,29 \%)$ of the cohort of 2650 shoulder injuries, reported to have sustained the shoulder injury during sports activities (table 1). In the most relevant age group from 6 to 69 years, the proportion was $36 \%$. Only one child below 6 years and 21 adults above 69 years, reported to be injured during sports. The diagnoses with the highest percentage of sports injuries were acromiclavicular joint injuries (sprain/distortion $54 \%$ and dislocation/separation 52\%). Twenty-one per cent of the patients with sports-related shoulder injuries reported to be injured in other communities or abroad.

\section{Young males}

Patients with sports injuries were younger. The median age was 28 years (IQR 20-43) compared with 43 (IQR 24-65, $\mathrm{p}<0.001)$ in those that got injured during other activities. The patients with a sports-related injury were also more often male (78\% in sports vs $52 \%$ in non-sports injuries, $\mathrm{p}<0.001)$. The OR of the shoulder injury being sports-related in males versus females was 3.3 (95\% CI, 2.7 to 4.0 ). When stratifying the overall shoulder injury incidence rates by age and gender, the sports-related rates were highest in young males, whereas the not sports-related rates were highest in the elderly (figures 1 and 2).

\section{Injury type and mechanism}

When comparing sports-related to non-sports-related shoulder injuries in patients from 6 to 69 years old, there was no difference in the proportion of shoulder injuries that were soft tissue injuries, fractures and dislocations/ separations (table 2). There was also no difference in the proportion caused by falls or acute overload. There were more collision/contact injuries among the patients who had injured the shoulder during sports (22\% vs $16 \%$, $\mathrm{p}<0.001)$.

\section{Sports associated with shoulder injury}

Football (soccer), cycling, skiing and martial arts were the sports activities most commonly causing acute shoulder injury, accounting for $58 \%$ of the sports injuries (table 1). In patients aged from 6 to 18 years, football dominated among both males and females (figure 3). In young adults between 19 and 29 years, there were only 35 sports injuries registered in females compared with 207 in men. Football still dominated in males $(29 \%, \mathrm{n}=59)$, but was almost absent in females $(n=1)$. The highest proportion of female injuries (32\%) was observed in the oldest age group, in which skiing accidents was the most common cause in both genders.

The distribution of diagnoses related to each of the most common sports is presented in figure 4 . When analysing the sports with 25 or more incidents in table 1, jogging and the high energy activities cycling and skiing caused a significantly larger proportion of fractures than the other sports $(p \leq 0.02)$. The proportion of dislocations was relatively high in martial arts but this was not significant compared with most of the other sports analysed.

\section{Rotator cuff tears}

Four per cent $(n=28 / 781)$ of the patients with sports-related shoulder injuries were diagnosed with a full-thickness or partial-thickness rotator cuff tear on MRI, similar to $4 \%$ in the group not injured during sports. The activity at the time of injury was skiing in 10 cases, 7 alpine and 3 cross-country. Skiing injuries thus accounted for 36\% $(\mathrm{n}=10 / 28)$ of the sports-related rotator cuff tears, and $9 \%$ $(n=10 / 106)$ of all rotator cuff tears in the cohort.

\section{Bias}

The SD of the mean shoulder injury incidence rate of the 15 districts was 53 (mean $417 / 10^{5}$ person-years, range 291-513), and the results did not indicate socioeconomic bias.

\section{DISCUSSION}

In the present study, we found that $29 \%$ of all acute shoulder injuries occurred during sports-related activities; $36 \%$ in the age group from 6 to 69 years. This is a higher proportion than in studies reporting all sports-related injuries in emergency departments. The US Centers for Disease Control and Prevention found that sports-related and recreation-related injuries comprised $16 \%$ of all unintentional injury-related emergency department visits, ${ }^{27}$ and in a Dutch study sports injuries accounted for $20 \%$ of all injuries in an emergency department over a 15 -year period. ${ }^{1}$ The higher percentage in the present study, indicating that the shoulder is susceptible to sports injuries, was partly to be expected from previous studies. A Swedish study of shoulder fractures and dislocations reported $29 \%$ $(\mathrm{n}=52 / 181)$ sports-related injuries in patients 15-64years old. ${ }^{28}$ Similarly, a Danish study of 104 soft tissue shoulder injuries in patients 19-75years old, also reported 29\% sports injuries. ${ }^{10}$ The highest proportion of sports injuries in the present study was found in patients with acromioclavicular 
Open access

Table 1 Number of patients with sports-related shoulder injuries

\begin{tabular}{|c|c|c|c|}
\hline & Males (\%) & Females (\%) & Total (\%) \\
\hline \multicolumn{4}{|l|}{ Sport } \\
\hline Football (soccer) & $133(22)$ & $7(4)$ & $140(18)$ \\
\hline Cycling & $91(15)$ & $21(12)$ & $112(14)$ \\
\hline Alpine skiing & $76(12)$ & $13(8)$ & $89(11)$ \\
\hline Cross-country skiing & $42(7)$ & $26(15)$ & $68(9)$ \\
\hline Martial arts & $40(7)$ & $4(2)$ & $44(6)$ \\
\hline Ice hockey & $31(5)$ & - & $31(4)$ \\
\hline Snowboarding & $25(4)$ & $5(3)$ & $30(4)$ \\
\hline Jogging & $11(2)$ & $14(8)$ & $25(3)$ \\
\hline Strength training * & $20(3)$ & $5(3)$ & $25(3)$ \\
\hline Skateboard & $18(3)$ & $1(1)$ & $19(2)$ \\
\hline Gym/physical education ${ }^{*} \dagger$ & $7(1)$ & $12(7)$ & $19(2)$ \\
\hline Handball & $8(1)$ & $7(4)$ & $15(2)$ \\
\hline Floorball & $8(1)$ & $4(2)$ & $12(2)$ \\
\hline Walking & $2(0)$ & $9(5)$ & $11(1)$ \\
\hline Basketball & $7(1)$ & $3(2)$ & $10(1)$ \\
\hline Horse riding & - & $8(5)$ & $8(1)$ \\
\hline \multicolumn{4}{|l|}{ Sports $<1 \%$ of shoulder injuries: } \\
\hline Bandy * & 7 & - & 7 \\
\hline Squash * & 6 & 1 & 7 \\
\hline Weightlifting * & 6 & 1 & 7 \\
\hline Dancing & 4 & 2 & 6 \\
\hline Gymnastics * & 3 & 2 & 5 \\
\hline Hiking * & 3 & 2 & 5 \\
\hline Ice skating * & 2 & 3 & 5 \\
\hline Volleyball * & 5 & - & 5 \\
\hline Field hockey* & 4 & - & 4 \\
\hline Motorcycle sport & 4 & - & 4 \\
\hline Roller skiing* & 4 & - & 4 \\
\hline Telemark skiing & 3 & 1 & 4 \\
\hline Treadmill* & - & 4 & 4 \\
\hline American football ${ }^{\star}$ & 3 & - & 3 \\
\hline Diving* & 2 & 1 & 3 \\
\hline Rugby* & 3 & - & 3 \\
\hline Swimming* & 2 & 1 & 3 \\
\hline Cheerleading* & - & 2 & 2 \\
\hline Dodgeball ${ }^{*}$ & 1 & 1 & 2 \\
\hline Rollerblades/roller skates & 2 & - & 2 \\
\hline Skydiving* & 2 & - & 2 \\
\hline Sports climbing* & 1 & 1 & 2 \\
\hline Table tennis* & 2 & - & 2 \\
\hline Trampoline & 2 & - & 2 \\
\hline Yoga* & 1 & 1 & 2 \\
\hline Sports with 1 injury $\ddagger$ & 14 & 6 & 20 \\
\hline Total sports $<1 \%$ & (14) & (17) & (15) \\
\hline Unknown & $5(1)$ & $3(2)$ & $8(1)$ \\
\hline Total & $610(100)$ & $171(100)$ & $781(100)$ \\
\hline
\end{tabular}

*Specification of 147 patients (19\%) ticked off as 'other sport' in the national accident registration and questionnaire.

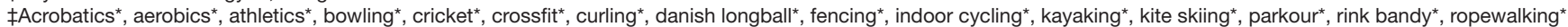
ski jumping*, surfing*, sledging/luge, water polo* and waterskiing/wakeboarding* 


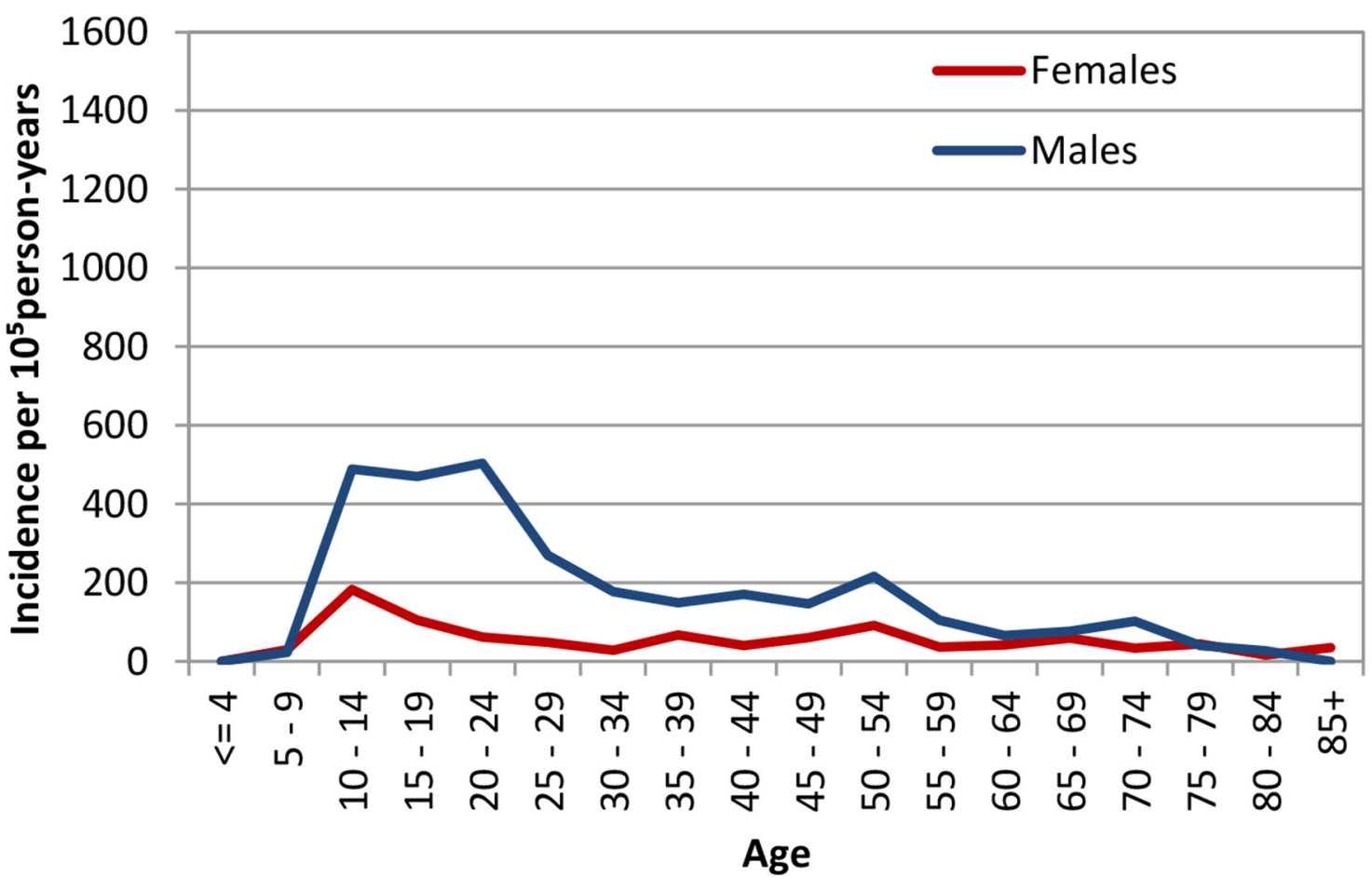

Figure 1 Sports-related shoulder injury incidence rates stratified by age and gender.

injuries (54\% and 52\%). An Italian study of isolated acromioclavicular dislocations in an urban population also found a high proportion of sports injuries $(43 \%){ }^{29}$

\section{Young males and missing females}

Males between 10 and 29years had an increased risk of sustaining a sports-related shoulder injury. Previous studies have described an increased general injury risk in young males, ${ }^{30}$ and of shoulder injuries like glenohumeral dislocations and fractures of the clavicle in particular. ${ }^{7173233}$ In the present population, the strongly increased total shoulder injury incidence rates in young males compared with females, ${ }^{6}$ were mainly due to a considerable male excess of sports-related shoulder injuries.

Equally interesting is the low shoulder sports injury incidence rates in young females. This could be explained by females injuring other anatomical regions, but in a Dutch

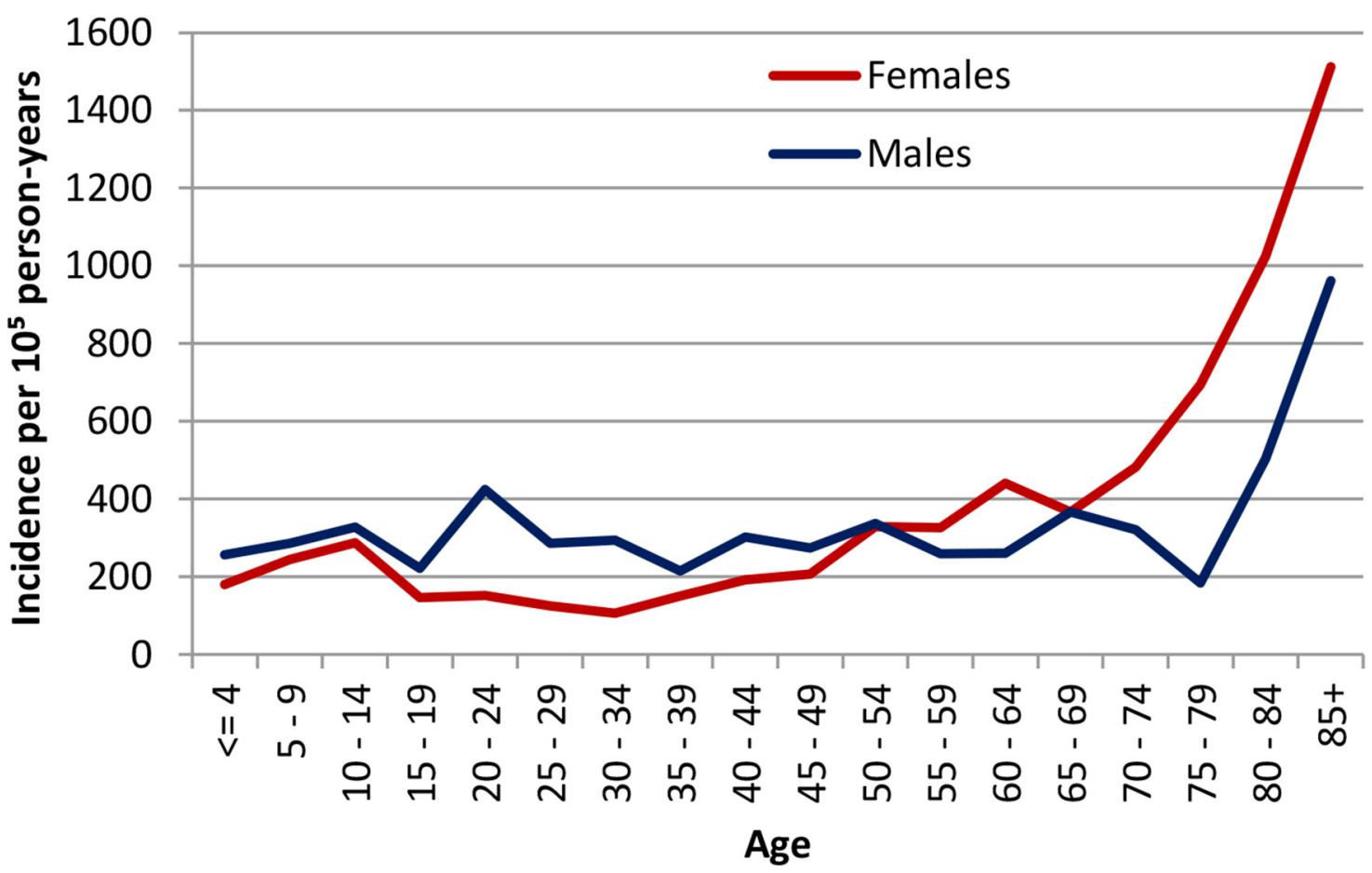

Figure 2 Not sports-related shoulder injury incidence rates stratified by age and gender. 
Table 2 Comparison of sports-related and non-sports-related shoulder injuries in patients 6-69years old

\begin{tabular}{|c|c|c|c|c|c|c|c|}
\hline \multirow[b]{2}{*}{ Activity } & \multirow[b]{2}{*}{ No } & \multirow[b]{2}{*}{$\%$} & \multirow[b]{2}{*}{ Median age (IQR) } & \multirow[b]{2}{*}{$\%$ females } & \multicolumn{3}{|c|}{ Injury mechanism \% } \\
\hline & & & & & falls & $\begin{array}{l}\text { contact/ } \\
\text { collision }\end{array}$ & acute overload \\
\hline Sports-related injuries: & 759 & 36 & $27(19-41)$ & 21 & 65 & 22 & 11 \\
\hline \multicolumn{8}{|l|}{ Non-sports-related injuries: } \\
\hline Payed work & 170 & 8 & $33(26-47)$ & 26 & 45 & 22 & 26 \\
\hline School & 67 & 3 & $11(8-13)$ & 51 & 69 & 22 & 6 \\
\hline \multicolumn{8}{|l|}{ Other activities by area: } \\
\hline Home & 392 & 18 & $42(27-57)$ & 52 & 65 & 11 & 15 \\
\hline \multicolumn{8}{|l|}{ Road, street, pavement } \\
\hline Pedestrian & 260 & 12 & $47(30-60)$ & 50 & 83 & 12 & 3 \\
\hline Bicycle & 125 & 6 & $37(27-49)$ & 27 & 80 & 20 & 0 \\
\hline Motor vehicle & 60 & 3 & $40(27-48)$ & 27 & 40 & 52 & 8 \\
\hline Other+unknown & 41 & 2 & $28(19-38)$ & 32 & 76 & 15 & 7 \\
\hline Nature/open landsc. & 41 & 2 & $31(23-55)$ & 37 & 78 & 7 & 12 \\
\hline Playground & 18 & 1 & $10(8-11)$ & 22 & 89 & 6 & 0 \\
\hline Other locations & 153 & 7 & $35(22-51)$ & 36 & 66 & 17 & 13 \\
\hline Unknown & 25 & 1 & $33(23-52)$ & 40 & 68 & 4 & 16 \\
\hline Non-sports-related inj. & 1352 & 63 & $37(24-53)$ & 41 & 68 & 16 & 11 \\
\hline Unknown sports/not & 23 & 1 & $51(35-61)$ & 30 & 30 & 13 & 4 \\
\hline All injuries aged 6-69 yrs & 2134 & 100 & $33(22-50)$ & 34 & 66 & 18 & 11 \\
\hline
\end{tabular}

emergency department study of 25120 sports injuries, females accounted for a higher proportion of the upper extremity $(37 \%)$ than lower extremity $(28 \%)$ injuries. ${ }^{1}$ Also, a Scottish study found similar accident and emergency department attendance rates in males and females when studying the subgroup of school/college sport and physical exercise, suggesting that with equal exposure, injury rates were comparable in both genders. ${ }^{30}$ There was also more gender similarity than differences in the patterns of injury in seven collegiate sports over a 15-year period in a US college. ${ }^{34}$ Future studies should investigate whether the low female rates are indicative of lower, or just different, physical activity, and in addition whether a difference in physical activity at young age may be

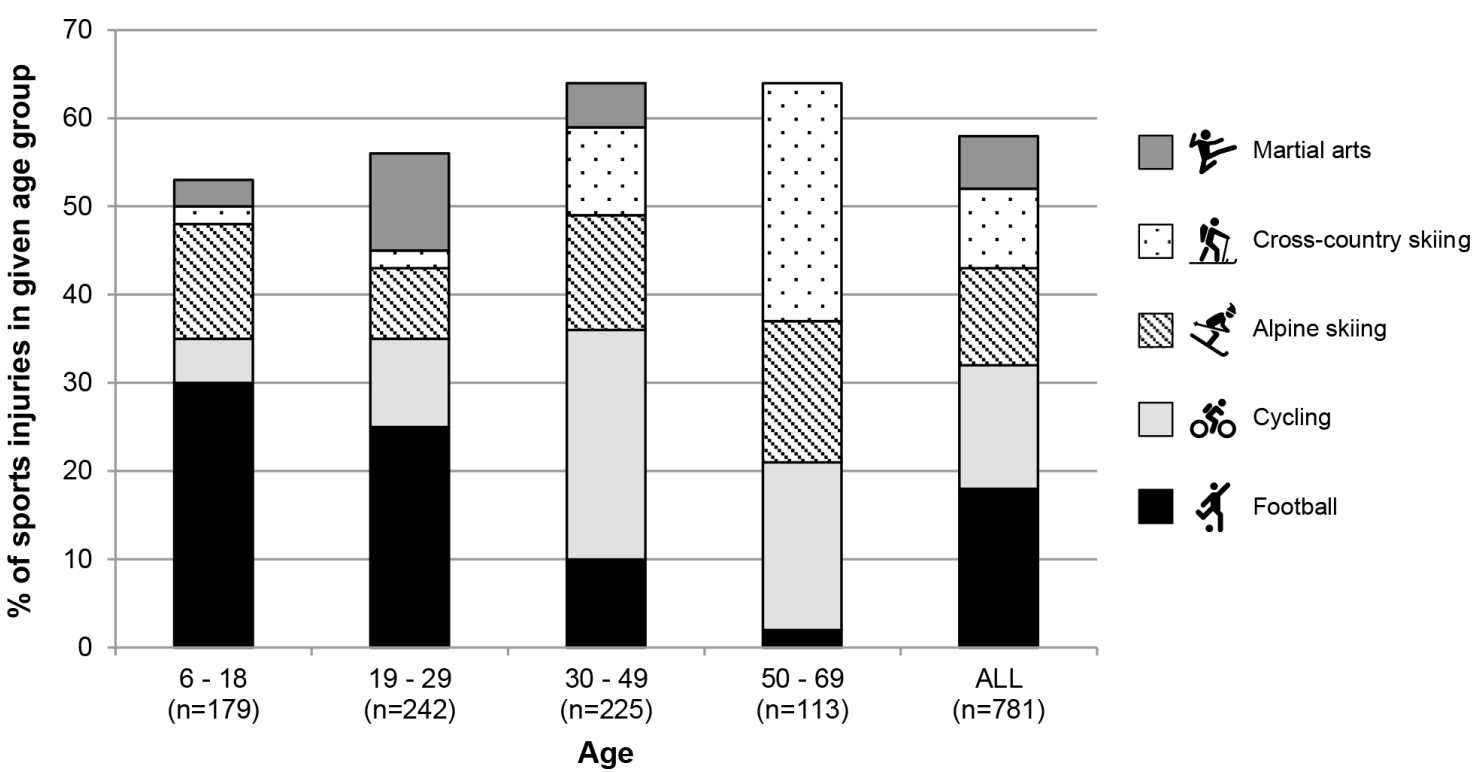

Figure 3 The five sports most commonly causing shoulder injury in the cohort. The percentage contributed by each sport to the total number of shoulder sports injuries in each age group is presented. Twenty-two patients with sports injuries were below 6 or above 69 years old. 


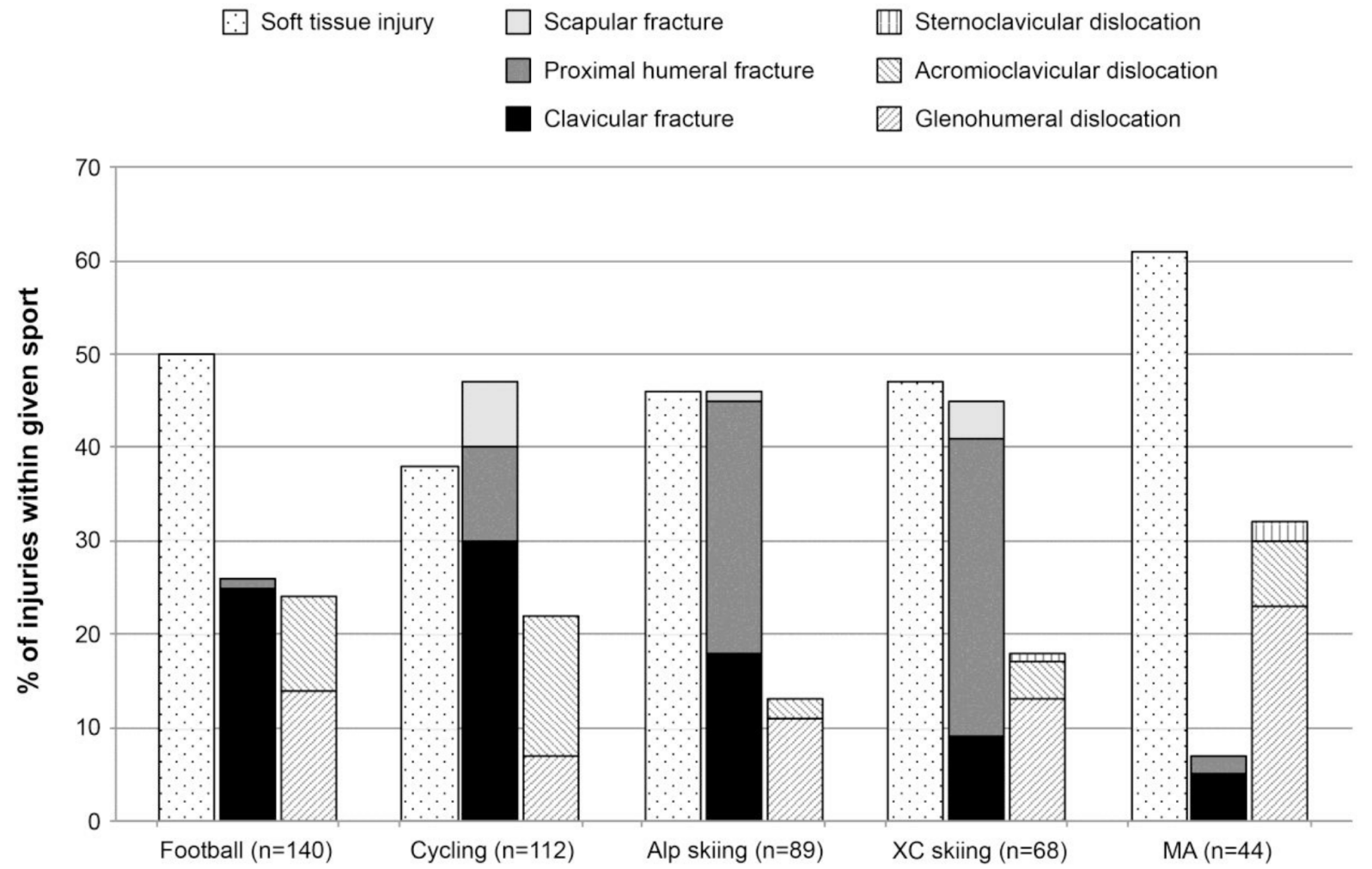

Figure 4 Types of shoulder injury in the five most common sports comprising 453 incidents with 475 shoulder diagnoses. Percentages were calculated according to number of incidents in each sport, and therefore add up to $>100 \%$ in some sports. Alp, alpine; MA, martial arts; XC, cross-country.

causally related to the increased female injury risk in the elderly (figures 1 and 2 ).

\section{Sports associated with shoulder injury}

The sports most commonly causing shoulder injuries in the present study partly reflect national traditions. ${ }^{15}$ This is a limitation regarding the generalisability of the results to other regions, and there are no similar studies on causes of shoulder injuries in the general population for comparison. In a Scottish study of sports-related fractures in patients $\geq 15$ years, however, the four most commonly reported sports were in descending order football, rugby, skiing/snowboarding and cycling, ${ }^{35}$ consistent with our study apart from rugby. Similarly, in the Dutch study of 25120 sports injuries, most upper extremity sports injuries were reported to occur in football. ${ }^{1}$ A different pattern was reported in a US study where the most common sports-related injuries were observed in basketball, recreational sports and American football. ${ }^{14}$ In spite of differences, sports like football, cycling and martial arts are popular over large parts of the world, and the results should be relevant to these countries. Age and gender are most probably confounding factors for the type of shoulder injury seen in each sport. On the other hand, popular sports activities in a certain age or gender may influence both overall shoulder injury rates and the rates of specific diagnoses in a given population.

\section{Rotator cuff tears}

The most common sport in patients with a partial-thickness or full-thickness rotator cuff tear was skiing, consistent with our finding that cross-country skiing was the most common sport causing shoulder injury in the population at risk between 50 and 69 years old, and alpine skiing the third. Two studies from European cities without nearby skiing facilities report similar findings: one-third of the sports shoulder injuries in a Danish study on soft tissue shoulder injuries were also skiing injuries. ${ }^{10}$ Similarly, the first study on the incidence of acute full-thickness tears from Southern Sweden, found that the sports-related cuff injuries were mainly caused by skiing. ${ }^{9}$

\section{Strengths and limitations}

The strength of the present study is the prospective design and the large unselected sample. Furthermore, the triangulation of injury mechanism data and the meticulous control of correct diagnoses. A previous study reported that the emergency department overestimated the fracture rate by $26 \%$ compared with the orthopaedic trauma unit in the same cohort of patients. ${ }^{36}$ As the Department of Orthopaedic Emergency is an integrated part of the Division of Orthopaedic Surgery, we believe the risk of misdiagnosis is low in our study.

The study has several limitations. First, we may have missed patients with injuries from other geographical areas that did not have follow-up at our department, even though as much as $11 \%$ of the cohort reported to 
be injured elsewhere. ${ }^{6}$ Second, the aim of comparing sports-related and non-sports-related injuries was not predefined, but a result of the observed incidence rate differences in young adults. Third, $19 \%$ reported to have been engaged in other than the 21 sports that could be ticked off. These sports were identified from the physician notes in the medical records, but could not be controlled against the accident registration and questionnaire like the rest. Fourth, the distinction between pre-existing age-related defects and acute tears of the rotator cuff on imaging is not well defined. The diagnosis in the present study was based on clinical findings confirmed by imaging. ${ }^{23}$ Finally, this study was not aimed at establishing the risk of shoulder injury in specific sports, which would require exposure measurement data.

\section{CONCLUSION}

Close to one-third of all shoulder injuries in the cohort occurred during sports activities. The most common sports associated with shoulder injuries were football, cycling, skiing and martial arts, but varied with age and gender. There was a higher proportion of fractures in high energy sports like skiing and cycling. Patients with sports-related injuries were younger and more often male. The results suggest that the generally increased risk of shoulder injuries in young males is largely explained by sports injuries. When comparing sport to non-sport injuries, there were no differences in the proportion of injuries that were fractures, dislocations and soft tissue injuries, but there were slightly more collision injuries in sports.

Acknowledgements We thank the entire staff at Department of Orthopaedic Emergency for the invaluable assistance in conducting this study, and Jon Olav Eikenes for graphic support. Preliminary results were presented as abstract and oral presentation at the 27th SECEC-ESSSE Congress in Berlin, 2017.

Contributors ME, SAS, LN, KM and JIB developed and designed the study. ME and SAS collected the data. ME and AHP conducted the statistical analysis. ME wrote the first and final draft of the manuscript. SAS, AHP and KM participated in the revision of the manuscript. LN and SM participated in the interpretation and revision of the first and final version of the manuscript. JIB supervised the study, participated in analysis, interpretation, and helped to draft and revise the manuscript.

Funding The study was supported by Sophies Minde Ortopedi AS, which is a subsidiary company of Oslo University Hospital. The company had no role in the study or writing process.

Competing interests None declared.

Patient consent for publication Not required.

Ethics approval In accordance with Norwegian legislation, the Office of the Privacy and Data Protection Officer of Oslo University Hospital approved the study as an internal audit Project with anonymous data on 17 February 2013 which is exempt from the obligation to report to the Data Inspectorate and Regional Committee for Medical and Health Research Ethics. The study was also registered With the Institutional Board as an internal audit Project.

Provenance and peer review Not commissioned; externally peer reviewed.

Data availability statement Data are available on reasonable request to the main author when permitted by the Office of the Privacy and Data Protection Officer of Oslo University Hospital.

Open access This is an open access article distributed in accordance with the Creative Commons Attribution Non Commercial (CC BY-NC 4.0) license, which permits others to distribute, remix, adapt, build upon this work non-commercially, and license their derivative works on different terms, provided the original work is properly cited, appropriate credit is given, any changes made indicated, and the use is non-commercial. See: http://creativecommons.org/licenses/by-nc/4.0/.

\section{REFERENCES}

1. Sytema R, Dekker R, Dijkstra PU, et al. Upper extremity sports injury: risk factors in comparison to lower extremity injury in more than 25000 cases. Clin J Sport Med 2010;20:256-63.

2. Engebretsen KB, Grotle M, Natvig B. Patterns of shoulder pain during a 14-year follow-up: results from a longitudinal population study in Norway. Shoulder Elbow 2015;7:49-59.

3. Luime JJ, Koes BW, Hendriksen IJM, et al. Prevalence and incidence of shoulder pain in the general population; a systematic review. Scand J Rheumatol 2004;33:73-81.

4. Ostör AJK, Richards CA, Prevost AT, et al. Diagnosis and relation to general health of shoulder disorders presenting to primary care. Rheumatology 2005;44:800-5.

5. Picavet HSJ, Schouten JSAG. Musculoskeletal pain in the Netherlands: prevalences, consequences and risk groups, the DMC(3)-study. Pain 2003;102:167-78.

6. Enger M, Skjaker SA, Melhuus K, et al. Shoulder injuries from birth to old age: a 1-year prospective study of 3031 shoulder injuries in an urban population. Injury 2018;49-1329. doi:10.1016/j. injury.2018.05.013. [Epub ahead of print: 22 May 2018]

7. Zacchilli MA, Owens BD. Epidemiology of shoulder dislocations presenting to emergency departments in the United States. J Bone Joint Surg Am 2010;92:542-9.

8. Nowak J, Mallmin H, Larsson S. The aetiology and epidemiology of clavicular fractures. A prospective study during a two-year period in Uppsala, Sweden. Injury 2000;31:353-8.

9. Aagaard KE, Abu-Zidan F, Lunsjo K. High incidence of acute fullthickness rotator cuff tears. Acta Orthop 2015;86:558-62.

10. Sørensen AKB, Bak K, Krarup AL, et al. Acute rotator cuff tear: do we miss the early diagnosis? A prospective study showing a high incidence of rotator cuff tears after shoulder trauma. J Shoulder Elbow Surg 2007;16:174-80.

11. Gibbs DB, Lynch TS, Nuber ED, et al. Common shoulder injuries in American football athletes. Curr Sports Med Rep 2015;14:413-9.

12. Longo UG, Loppini $M$, Berton $A$, et al. Shoulder injuries in soccer players. Clin Cases Miner Bone Metab 2012;9:138-41.

13. McCall D, Safran MR. Injuries about the shoulder in skiing and snowboarding. Br J Sports Med 2009;43:987-92.

14. Conn JM, Annest JL, Gilchrist J. Sports and recreation related injury episodes in the US population, 1997-99. Inj Prev 2003;9:117-23.

15. Boyce SH, Quigley MA. Review of sports injuries presenting to an accident and emergency department. Emerg Med J 2004;21:704-6.

16. Lofthus CM, Frihagen F, Meyer HE, et al. Epidemiology of distal forearm fractures in Oslo, Norway. Osteoporos Int 2008;19:781-6.

17. Liavaag $S$, Svenningsen $S$, Reikerås $O$, et al. The epidemiology of shoulder dislocations in Oslo. Scand J Med Sci Sports 2011;21:e334-40.

18. Statistics Norway. Available: https://www.ssb.no/statistikkbanken/ selectvarval/Define.asp? subjectcode=\&Productld=\&MainTable= FolkemBydEttar\&nvl=\&PLanguage $=1 \&$ nyTmpVar=true\& CMSSubjectArea=befolkning\&KortNavnWeb=folkemengde\& StatVariant=\&checked=true [Accessed 10 Mar 2017].

19. Robson C, McCartan K. Real world research. 4th ed. Wiley, 2015.

20. Greenspan A, Beltran J. Orthopedic imaging: a practical approach. 6th ed. Wolters Kluwer Health, 2015: 153-5.

21. Walton J, Mahajan S, Paxinos A, et al. Diagnostic values of tests for acromioclavicular joint pain. J Bone Joint Surg Am 2004;86:807-12.

22. Jain NB, Yamaguchi K. History and physical examination provide little guidance on diagnosis of rotator cuff tears. Evid Based Med 2014;19:108

23. Jain NB, Luz J, Higgins LD, et al. The diagnostic accuracy of special tests for rotator cuff tear: the row cohort study. Am J Phys Med Rehabil 2017;96:176-83.

24. Yamaguchi K, Ditsios K, Middleton WD, et al. The demographic and morphological features of rotator cuff disease. A comparison of asymptomatic and symptomatic shoulders. J Bone Joint Surg Am 2006;88:1699-704.

25. Sher JS, Uribe JW, Posada A, et al. Abnormal findings on magnetic resonance images of asymptomatic shoulders. J Bone Joint Surg Am 1995;77:10-15.

26. Moosmayer S, Smith H-J, Tariq R, et al. Prevalence and characteristics of asymptomatic tears of the rotator cuff: an ultrasonographic and clinical study. J Bone Joint Surg Br 2009;91:196-200.

27. Centers for Disease Control and Prevention (CDC). Nonfatal sportsand recreation-related injuries treated in emergency departments-- 
United States, July 2000-June 2001. MMWR Morb Mortal Wkly Rep 2002;51:736-40.

28. Nordqvist A, Petersson CJ. Incidence and causes of shoulder girdle injuries in an urban population. J Shoulder Elbow Surg 1995;4:107-12.

29. Chillemi C, Franceschini V, Dei Giudici L, et al. Epidemiology of isolated acromioclavicular joint dislocation. Emerg Med Int 2013;2013:1-5.

30. McQuillan R, Campbell H. Gender differences in adolescent injury characteristics: a population-based study of hospital A\&E data. Public Health 2006;120:732-41.

31. Menon MRG, Walker JL, Court-Brown CM. The epidemiology of fractures in adolescents with reference to social deprivation. $J$ Bone Joint Surg Br 2008;90:1482-6.
32. Robinson CM. Fractures of the clavicle in the adult. epidemiology and classification. J Bone Joint Surg Br 1998;80:476-84.

33. Herteleer M, Hoekstra H, Nijs S. Diagnosis and treatment of clavicular fractures in Belgium between 2006 and 2015. J Shoulder Elbow Surg 2018;27:1512-8.

34. Sallis RE, Jones K, Sunshine S, et al. Comparing sports injuries in men and women. Int J Sports Med 2001;22:420-3.

35. Aitken SA, Watson BS, Wood AM, et al. Sports-Related fractures in South East Scotland: an analysis of 990 fractures. J Orthop Surg 2014;22:313-7.

36. Aitken SA, Rodrigues MA, Duckworth AD, et al. Determining the incidence of adult fractures: how accurate are emergency department data? Epidemiol Res Int 2012;2012:1-7. 